\title{
Gelişme Geriliği, Kronik Ishal veya Tekrarlayan Akciğer Enfeksiyonu Nedeniyle Ter Testi Taraması Sonrası Tanı Konan Kistik Fibrozisli Çocukların Klinik ve Demografik Özellikleri
}

\author{
Clinical and Demographic Features of Children Diagnosed with Cystic \\ Fibrosis after Sweat Test Screening for Failure to Thrive, Chronic Diarrhea or \\ Recurrent Pulmonary Infections
}

Çapan Konca, Ali Güneş*, Velat Şen*, Servet Yel*, Illyas Yolbaş*, Aydın Ece*, Mehmet Fuat Gürkan*

Adıyaman Üniversitesi Tıp Fakültesi, Çocuk Sağlğı ve Hastalıkları Anabilim Dalı, Adıyaman, Türkiye

*Dicle Üniversitesi Tıp Fakültesi, Çocuk Sağlığı ve Hastalıkları Anabilim Dall, Diyarbakır, Türkiye

Yazışma Adresi/Address for Correspondence Dr. Çapan Konca, Adıaman Üniversitesi Tip Fakültesi, Çocuk Sağlığı ve Hastallkları Anabilim Dalı, Adıaman, Türkiye Gsm: +905054896904 E-posta:dr.capan@hotmail.com

Geliş Tarihi/Received: 27.05.2013 Kabul Tarihi/Accepted: 25.10.2013

(c) Güncel Pediatri Dergisi, Galenos Yayınevi tarafindan basılmıştr.

(c) The Journal of Current Pediatrics, published by Galenos Publishing.

\section{ÖZET}

Giriş: Bu çalışmada, tekrarlayan akciğer enfeksiyonu, kronik ishal ve gelişme geriliği şikayetleri ile başvuran ve özgül tanı alamayan hastalarda kistik fibrozis (KF) sıkığını araştırarak bu hastaların demografik, klinik ve laboratuvar özelliklerinin araştırıması amaçlandı.

Gereç ve Yöntem: Bu çalışmada, KF tanısı, KF için bir veya daha fazla karakteristik fenotopik özellik gösteren çocuklarda terde kondüktivite ölcümü yapılarak kondu. Değerlendirmede, terde klor konsantrasyonu $59 \mathrm{mmol} / \mathrm{tt}$ 'nin altı negatif, $60-79 \mathrm{mmol} / \mathrm{tt}$ arası sınırda pozitif ve $80 \mathrm{mmol} / \mathrm{t}$ 'nin üzeri pozitif ter testi sonucu olarak kabul edildi. Atipik KF tanısı sınırda ter testi pozitifliğine ilave olarak genetik mutasyon, nazal potansiyel farkı ve elastaz aktivitesi gibi destekleyici faktörlerle birlikte kondu.

Bulgular: Çalışmaya toplam 356 hasta dahil edildi. Yirmi hastaya $(\% 5,6) \mathrm{KF}$ tanısı kondu. Hastaların yaş ortalaması 19,3 $\pm 18,1$ ay idi ve 234 (\%65,7)'ü erkekti. Tekrarlayan akciğer enfeksiyonu ile başvuran 90 hastanın 14'üne $(\% 15,5)$, kronik ishal yakınması ile başvuran 99 hastanın 10 'una $(\% 10,1)$ ve belirgin büyüme ve gelişme geriliği olan 100 hastanın 7'sine (\%7) KF tanısı kondu. Tanı konan hastaların temel başvuru yakınmaları ateş, solunum sistemi yakınmaları, gelişme geriliği ve kronik ishal idi. Toplam 356 hastaya 430 ter testi yapildı ve ölçüm sonucu $60 \mathrm{mmol} / \mathrm{t}$ üzerinde olan 33 hastadan 20 tanesine $\mathrm{KF}$ tanısı konuldu.

Sonuç: Kronik ishal, tekrarlayan akciğer enfeksiyonu ve gelişme geriliği ile başvuran hastalarda KF ayıııı tanılar arasında düşüuülmelidir. Beyaz ırkta yaklaşık 3000'de 1 olan KF sıkığı hasta grubumuzda \%5,6 oranıyla yüksek bulunmuştur. (Güncel Pediatri 2013; 11: 96-101)

Anahtar kelimeler: Akciğer enfeksiyonu, büyüme geriliği, kistik fibrozis, kronik ishal, ter testi

\section{SUMMARY}

Introduction: The aim of this study was to investigate the incidence of cystic fibrosis (CF) in patients with recurrent pulmonary infection, chronic diarrhea and failure to thrive having no specific diagnosis and also to investigate the demographic features, and clinic and laboratory findings of such patients.

Materials and Methods: The diagnosis of CF has been established through measuring the sweat conductivity in children presenting with one or more characteristic phenotypic features of CF. A chloride concentration lower than $59 \mathrm{mmol} / \mathrm{l}$ was interpreted as negative; $60-79$ as borderline and over 80 as positive. A borderline sweat test result supported with genetic mutation, nasal potential difference or elastase activity was diagnosed as atypical CF.

Results: A total of 356 patients fulfilled the study criteria. Twenty (5.6\%) patients were diagnosed as CF. The mean age of the patients was $19.3 \pm 18.1$ months and $234(65.7 \%)$ of them were boys. Of the patients suffered from recurrent pulmonary infection, chronic diarrhea and failure to thrive; $15.5 \%$, $10.1 \%$, and $7 \%$ were diagnosed as CF, respectively. Major presenting complaints were fever, respiratory tract diseases, failure to thrive, and chronic diarrhea in patients with CF. A total of 430 sweat tests were applied to 356 patients and 20 of the 33 patients with a test resulting over $60 \mathrm{mmol} / \mathrm{L}$ were diagnosed as CF.

Conclusions: CF should be considered for the differential diagnosis of the patients presented with chronic diarrhea, recurrent pulmonary infection, and failure to thrive. While the incidence of CF in white people is approximately 1 in 3000 individuals, we found a higher rate of $5.6 \%$ in our study group. (Journal of Current Pediatrics 2013; 11: 96-101)

Key words: Chronic diarrhea, cystic fibrosis, failure to thrive, pulmonary infection, sweat test 


\section{Giriș}

Kistik fibrozis (KF) beyaz ırkta daha sık görülen genetik bir hastalıktır $(1,2)$. Kronik obstrüktif akciğer hastalı̆̆ı, pankreasın ekzokrin yetersizliği ve yüksek ter elektrolit düzeylerinden oluşan klasik üç klinik bulgu hastaların \%90'ında bulunmaktadır (3-5). KF birçok organ epitelinde transmembran klor kanalı görevi yapan bir proteini kodlayan kistik fibrozis transmembran regülatör (KFTR) genindeki mutasyonlar sonucu oluşur. Yedinci kromozomun uzun kolunda yer alan KFTR geninin 1989'da klonlanmasından sonra 1500'ün üzerinde farklı mutasyon tanımlanmış ve gen ürününün yapı ve fonksiyonu ile ilgili bilgi birikimi hızla artmıştır (6).

$\mathrm{KF}$, yenidoğanda mekonyum ileusu ve uzamış sarılık gibi bulgularla kendini gösterir. Süt çocukluğu döneminde ise ishal, büyüme geriliği, psödobartter tablosu, tekrarlayan bronşiyolit ve öpülünce tuz tadı alınması gibi bulgular ön plana geçer. Solunum yollarında, önce $S$. aureus, $H$. influenza, daha sonra $P$. aeruginoza gibi mikroorganizmalar kolonize olur. Daha büyük yaştaki çocuklarda ise pansinüzit, nazal polipozis, bronşektazi, pnömotoraks, hemoptizi, diyabet, infertilite gibi belirti ve bulgular kendini gösterir. Erken tanı ve tedaviyle uzun dönem prognozu iyileştirmek amaçlanmaktadır. Tanının ter testi ve mutasyon analizi ile doğrulanması gereklidir.

$\mathrm{Bu}$ çalışmada, tekrarlayan akciğer enfeksiyonu, kronik ishal ve gelișme geriliği şikayetleri ile başvuran ve spesifik tanı alamayan hastalarda ter testi yapılarak KF sıklığının araştıııması amaçlanmıştır. Elimizdeki verilere göre; ülkemizde malnütrisyonlu ve tekrarlayan akciğer enfeksiyonlu hastalarda KF sıklığı ile ilgili sadece bir çalışma mevcut olup, çalışmamız tekrarlayan akciğer enfeksiyonu, kronik ishal ve gelişme geriliği olan hastalarda KF sıklığının araştırılığı ilk çalışmadır.

\section{Gereç ve Yöntem}

Bu çalışmada Dicle Üniversitesi Tıp Fakültesi Pediatri Kliniğine Ocak 2006 ve Ocak 2008 tarihleri arasında kronik ishal, tekrarlayan akciğer enfeksiyonu, gelişme geriliği, nazal polipozis, psödobartter sendromu ve mekonyum ileusu gibi KF şüphesi uyandıran şikayetlerle başvuran ve daha önce tanı almamış hastalarda ter testi yapılarak, KF sıkığı araştıııldı ve hastaların demografik, klinik ve laboratuvar özellikleri incelendi. Bu klinik özellikleri açıklayacak başka bir kronik hastalığı olan çocuklar çalışmaya dâhil edilmedi. Ishal yakınmasının üç haftadan daha fazla devam etmesi, kronik ishal olarak kabul edildi. Bir yıl içinde iki pnömoni atağı geçirilmesi veya yaşamı süresince en az üç kez pnömoni atağı geçiren ve ataklar arasında klinik ve radyografik olarak normal olan hastalar tekrarlayan pnömoni olarak kabul edildi (7). Boyları ve/ veya vücut ağırlıkları yaşlarına göre 3. persentilin altında
(<-2 SDS) olan hastalar büyüme ve gelişme geriliği olarak kabul edildi.

Prospektif olan bu çalışmada, KF için bir veya daha fazla karakteristik fenotipik özellik gösteren çocuklarda terde kondüktivite ölçümü yapılarak KF tanısı konulması amaçlandı. Değerlendirmede; $59 \mathrm{mmol} / \mathrm{lt}$ 'nin altı negatif ölçüm, $60-79 \mathrm{mmol} / \mathrm{tt}$ arası sınırda pozitif ve $80 \mathrm{mmol} /$ It'nin üzeri pozitif olarak kabul edildi. Tüm pozitif ve şüpheli hastalara en az iki kez ter testi yapıldı.

Çalışmaya alınan tüm hastalar yaş, cinsiyet, hastaneye başvuru ve hastanede yatış sayısı, ebeveynlerin akrabalık durumu, kardeş sayısı, ölen kardeş sayısı, ilk şikayet bașlama yașları, bașvuru șikayetleri ve bulguları, rutin laboratuvar özellikleri, radyolojik bulguları ve klinik durumları açısından incelendi.

Hastaların ter testi değerlendirmesi NANODUCT ${ }^{\circledR}$ marka cihazla (Wescor Inc, Utah, USA) iki aşamada gerçekleştirildi. Birinci aşamada pilokarpin jeller yardımıyla temizlenmiş ve kurulanmış olan ön kolda ter stimüle edilirken; ikinci aşamada aynı alanda özel ölçüm başlıkları ile terde kondüktivite ölçümü yapıldı. Ölçüm sonuçları $\mathrm{mmol} / \mathrm{L}$ cinsinden ifade edildi. Tüm pozitif ya da şüpheli ölçümler en az iki kez tekrarlandı.

Izlemdeki hastaların klinik özelliklerini Shwachman skorlama sistemi (8), radyolojik özellikleri ise modifiye Chripsin ve Norman skorlama sistemi (9) ile değerlendirildi. Hastaların boy, kilo ve gelişimlerinin değerlendirilmesinde Neyzi ve arkadaşlarının büyüme-gelişme eğrilerinden (10) faydalanıldı.

Tanı konulan hastalardan enfeksiyon bulguları olan hastalara antibiyotik, solunum sistem yakınması olanlara ilave olarak mukolitik tedavi ve postüral drenaj, gelişme geriliği ve malabsorbsiyonu olan hastalara pankreatik enzim preparatı, tüm hastalara diyet uzmanlarından yardım alınarak uygun diyet programı verildi.

\section{İstatistiksel Analiz}

Istatistiksel değerlendirme için SPSS 12.0 (SPSS Inc, IL) bilgisayar programı kullanıldı. Istatistiksel analizde tanımlayıcı testler ve ki-kare testi uygulandı. P değeri 0,05 'in altı anlamlı kabul edildi.

\section{Bulgular}

Bu çalışmada Ocak 2006- Ocak 2008 tarihleri arasında Dicle Üniversitesi Tıp Fakültesi Çocuk Kliniğine bașvuran hastalardan KF şüphesi uyandıran 356 hasta değerlendirildi ve 20 hastaya KF tanısı konuldu.

Çalışmada, 356 hastaya toplam 430 ter testi yapıldı ve ölçüm sonucu $60 \mathrm{mmol} /$ It'nin üzerinde olan 33 hastadan 20 tanesine KF tanısı konuldu. Illk ter testi 80 mmol/lt'nin üzerinde ölçülen 6 hastadan birisinin kontrol ter testleri iki kez normal olduğu için yanlış pozitiflik olarak kabul edildi ve KF tanısı konulmadı. Ayrıca, ilk test sonuçları 60-80 
$\mathrm{mmol} / \mathrm{lt}$ arasında olan 27 hastanın tümünün ter testleri tekrarlandı ve genetik mutasyonlar araștırıldı. Genetik inceleme, kontrol ter testleri sonuçları, gaitada pankreatik elastaz düzeyleri ve hastaların klinik özellikleri göz önünde bulundurularak 15 hastaya atipik KF tanısı konuldu (Tablo 1). Genetik inceleme sonucunda 12 hastada KF ile uyumlu mutasyon saptandı, üç hastada mutasyon saptanmadığı halde klinik özellikler ve tekrarlayan ter testleri 60-80 $\mathrm{mmol} / \mathrm{lt}$ arasında ölçüldüğü için atipik KF kabul edildi. Bu üç hastanın klinik izlemleri ve tedaviye yanıtları atipik KF ile uyumlu idi.

Çalışmaya alınan çocukların 234'ü $(\% 65,73)$ erkek olup, tanı konan hastaların 15 'i $(\% 75,0)$ erkekti $(p>0,05)$. Çalışmaya alınan hastaların yaş ortalaması 19,3 $\pm 18,1$ ay, KF tanısı konan hastaların yaş ortalaması 17,5 $\pm 16,5$ ay idi $(p>0,05)$. Değerlendirmeye alınan ve KF tanıS konan hastaların ilk şikayet başlama yaşları sırasıyla $11,3 \pm 26,5$ ay ve $14 \pm 33,6$ ay $(p>0,05)$ olup her iki hasta grubunda çocukların yaklaşık \%75'i yaşamın ilk 6 ayında semptomatik olmaya başlamıştı.

Çalışmaya alınan hastalarda ve KF tanısı konan hastalarda ateş, tekrarlayan solunum sistemi yakınmaları, gelişme geriliği ve kronik ishal yaygın klinik özelliklerdi (Tablo 2).

Tekrarlayan pnömoni yakınması ile başvuran 90 hastadan $16(\% 17,7)$ tanesinde ter testi $60 \mathrm{mmol} / \mathrm{lt}$ 'nin üzerinde saptanırken, bu hastalardan 14'ünde $(\% 15,5)$

\begin{tabular}{|l|l|l|}
\hline $\begin{array}{l}\text { Tablo 1. Ter testi yapılan ve kistik fibroz (KF) tanısı alan } \\
\text { hastalarda ter testi sonuçları }\end{array}$ \\
\hline Ter testi sonucu (mmol/t) & $\begin{array}{l}\text { Ter testi yapılan } \\
\text { hastalar n (\%) }\end{array}$ & $\begin{array}{l}\text { KF tanısı alan } \\
\text { hastalar n (\%) }\end{array}$ \\
\hline$<60$ & $311(87,4)$ & - \\
\hline $60-80$ & $27(7,5)$ & $15(75)$ \\
\hline$>80$ & $6(1,7)$ & $5(25)$ \\
\hline Başarısız test & $12(3,4)$ & - \\
\hline
\end{tabular}

Tablo 2. Çalışmaya alınan ve kistik fibroz (KF) tanısı alan hastaların başvuru yakınmaları

\begin{tabular}{|l|l|l|l|}
\hline Yakınma & $\begin{array}{l}\text { Incelenen } \\
\text { tüm hastalar } \\
\mathbf{( N = 3 5 6 )} \mathbf{n}(\%)\end{array}$ & $\begin{array}{l}\text { KF tanısı } \\
\text { alan hastalar } \\
\mathbf{( N = 2 0 )} \mathbf{n}(\%)\end{array}$ & $\mathbf{p}$ \\
\hline Ateş & $332(93,3)$ & $18(90)$ & 0,147 \\
\hline Öksürük & $304(85,4)$ & $12(60)$ & 0,007 \\
\hline Nefes darlığı & $260(73,0)$ & $11(55)$ & 0,156 \\
\hline Hırıltı & $252(70,7)$ & $12(60)$ & 0,444 \\
\hline Gelişme geriliği & $100(28,1)$ & $7(35)$ & $<0,001$ \\
\hline Kronik ishal & $99(27,8)$ & $10(50)$ & 0,061 \\
\hline $\begin{array}{l}\text { Tekrarlayan } \\
\text { pnömoni }\end{array}$ & $90(25,3)$ & $14(70)$ & $<0,001$ \\
\hline
\end{tabular}

KF tanısı kondu. Kronik ishal yakınması ile başvuran 99 hastadan 11 'inde $(\% 11,1)$ ter testi $60 \mathrm{mmol} / \mathrm{lt}$ 'nin üzerinde saptandı ve bu hastalardan 10'unda $(\% 10,1) \mathrm{KF}$ tanısı kondu. Belirgin büyüme ve gelişme geriliği olan 100 hastadan 8'inde (\%8) ter testi $60 \mathrm{mmol} / \mathrm{lt}$ 'nin üzerinde saptandı ve 7 (\%7) hastaya KF tanısı kondu.

Hastaların detaylı öyküsü alındığında, değerlendirilen hastaların \%68,2'si ve KF tanısı alan hastaların \%80'i daha önce en az $10 \mathrm{kez}$ hastaneye başvurmuştu. Ayrıca, değerlendirilen hastaların \%86,8'i ve KF tanısı alan hastaların \%85'i en az bir defa hastanede yatılı olarak tedavi görmüştü (Tablo 3).

Değerlendirmeye alınan çocukların ebeveynlerinin $\% 50$ 'sinde akrabalık yok iken; 1 . derece akrabalık \%33,1, 2. derece akrabalık \%14,1 ve 3. derece/uzak akrabalık \%2,8 olarak saptandı. KF tanısı alan hastaların ebeveynlerinin \%50'si akraba değilken ebeveynlerin \%45'inde 1. derece akrabalık, \%5'inde ise 2. derece akrabalık olduğu görüldü.

KF tanısı konan hastaların \%85'i en az dört kardeșe sahipti. KF tanısı konan 20 hastadan 12'sinde kardeș ölüm öyküsü mevcuttu. KF tanılı çocukların birinde 6 kardeş ölüm öyküsü saptanmış iken, sadece 8 hastanın ölen kardeş öyküsü yoktu.

Hem çalışmaya alınan hem de çalışma sonunda tanı konan hastalarda belirgin gelişme geriliği olduğu görüldü (Tablo 4).

Hastaların bazı laboratuvar değerlerine bakıldığında incelenen hastaların 21'inde $(\% 5,9)$ transaminaz yüksekliği, 15 'inde $(\% 4,2)$ psödobartter sendromu ve bir hastada da hiperürisemi mevcut iken; tanı alan hastaların iki tanesinde asemptomatik transaminaz yüksekliği, iki tanesinde ise psödobartter sendromu saptandı (Tablo 5).

Shwachman klinik skorlamasına göre tanı alan 20 hastanın; \%5'i çok iyi, \%60' i iyi, \%25'i hafif, \%5'i orta, \%5'i ise ağır derecede hasta grubundaydı. Tanı alan hastalar

Tablo 3. Çalıșmaya alınan ve kistik fibroz (KF) tanısı konan hastaların daha önce hastaneye başvuru ve hastanede yatış durumları

\begin{tabular}{|c|c|c|c|c|}
\hline & & $\begin{array}{l}\text { Değerlendirilen } \\
\text { çocuklar n (\%) }\end{array}$ & $\begin{array}{l}\text { KF tanıSı alan } \\
\text { hastalar n (\%) }\end{array}$ & p \\
\hline \multirow{4}{*}{$\begin{array}{l}\text { Hastaneye } \\
\text { başvuru } \\
\text { sayısı }\end{array}$} & $1-5$ & $53(14,9)$ & $1(5)$ & \multirow{4}{*}{0,752} \\
\hline & $5-10$ & $60(16,9)$ & $3(15)$ & \\
\hline & $10-20$ & $74(20,7)$ & $6(30)$ & \\
\hline & $>20$ & $169(47,5)$ & $10(50)$ & \\
\hline \multirow{5}{*}{$\begin{array}{l}\text { Hastanede } \\
\text { yatış sayısı }\end{array}$} & Yok & $47(13,2)$ & $1(5)$ & \multirow{5}{*}{0,163} \\
\hline & $1-3$ & $179(50,3)$ & $8(40)$ & \\
\hline & $3-5$ & $87(24,5)$ & $7(35)$ & \\
\hline & $5-10$ & $35(9,8)$ & $2(10)$ & \\
\hline & $10>$ & $8(2,2)$ & $2(10)$ & \\
\hline
\end{tabular}




\begin{tabular}{|c|c|c|c|c|}
\hline \multirow[b]{2}{*}{ Persentil } & \multicolumn{2}{|c|}{ Boy n (\%) } & \multicolumn{2}{|c|}{ Ağırlık n (\%) } \\
\hline & Değerlendirilen & KF tanısı konan & Değerlendirilen & KF tanısı konan \\
\hline$<3 . p$ & $100(28,1)$ & $7(35,0)$ & $85(23,9)$ & $9(45,0)$ \\
\hline 3-10. p & $87(24,5)$ & $6(30,0)$ & $58(16,3)$ & $6(30,0)$ \\
\hline 10-25. p & $54(15,1)$ & $4(20,0)$ & $64(17,9)$ & $3(15,0)$ \\
\hline 25-50. p & $30(8,5)$ & $1(5,0)$ & $65(18,3)$ & - \\
\hline 50. p & $67(18,8)$ & $1(5,0)$ & $56(15,8)$ & $2(10,0)$ \\
\hline $50-75 . p$ & $17(4,8)$ & $1(5,0)$ & $28(7,8)$ & - \\
\hline 75-90. p & $1(0,2)$ & - & - & - \\
\hline
\end{tabular}

Tablo 5. Çalıșmaya alınan ve kistik fibroz (KF) tanısı alan hastalarda önemli laboratuvar değerleri

\begin{tabular}{|l|l|l|l|}
\hline Laboratuvar testi & $\begin{array}{l}\text { Incelenen } \\
\text { çocuklar } \\
\mathbf{n}(\%)\end{array}$ & $\begin{array}{l}\text { KF tanısı } \\
\text { alan çocuklar } \\
\mathbf{n}(\%)\end{array}$ & P \\
\cline { 1 - 2 } AST/ALT yüksekliği & $21(5,9)$ & $2(10)$ & \multirow{2}{*}{0,580} \\
\hline Psödobartter varlığı & $15(4,2)$ & $2(10)$ & \\
\hline Açıklanamayan hiponatremi & $4(1,1)$ & $2(10)$ & \\
\hline Üre/kreatinin yüksekliği & $1(0,3)$ & - & \\
\hline
\end{tabular}

akciğer grafi bulgularına dayalı modifiye Chripsin-Norman skorlamasına göre değerlendirildiğinde; sadece 4 hastanın 11 ve üzerinde puan aldığı tespit edilirken; geri kalan hastalarda hafif değişiklikler olduğu tespit edildi.

\section{Tartışma}

KF hastalarında birçok faktörden dolayı gelișme geriliği oluşabilmektedir. Bunların bașında artmış enerji ihtiyacı, malabsorpsiyon, yetersiz enerji alımı, karaciğer hastalığı ve diabetes mellitus gelmektedir. Hastaların \%85-90'ında mevcut olan pankreas yetmezliği yağ, protein ve diğer besin maddelerinin malabsorpsiyonuna neden olabilmektedir (11). Başlangıçta pankreatik yetersizliği olmayanlarda da zamanla pankreas yetmezliği gelişebilir (12).

Yapılan çalışmalarda KF'li hastalarda istirahat halindeki enerji tüketiminin normal kontrollere göre \%4-33 oranında artmış olduğu saptanmıştır. Almanya'da 3. basamak bir çocukhastanesinde seri halde gelen veyatırılan, seçilmemiş 475 hastanın \%24,1'inde malnütrisyon saptanmıștır. Bu hastalara $\% 40,0$ oranında mental retardasyon, $\% 34,5$ oranında enfeksiyon hastalığı ve \%33,3 oranında KF tanısı konmuștur (13). Çalıșmamızda da malnütrisyon, gelișme geriliği ve kilo alamama şikayeti ile başvuran 145 hastadan 17'sinde $(\% 11,7)$ KF tanısı kondu ve 2 hastamızda karaciğer tutulumu mevcuttu. Ayrıca 104 KF olgusunun değerlendirildiği bir çalışmada tanı esnasında hastaların \%69,9'unun ağırlığı, \%56,6'sının ise boyu 10. persentilin altında ölçülmüștür (14). Çalıșmamızın sonuçları da bu literatür bilgisi ile uyumludur. Ter testi yapılan hastaların, hem vücut ağırlıkları hem de boyları açısından yaklaşık $\% 77$ 'si 50. persentilin altında idi.

Bir çalışmada KF tanısı alan hastaların, ilk şikâyet başlama yaşı ortalama 3 ay, tanı alma yaşı ise 2 yıl 4 ay olarak bulunmuştur (15). Başka bir çalışmada tanı alan hastaların, ilk şikâyet başlama yaşı ortalama 2,3 ay, tanı alma yaşı ise 14,3 ay olarak saptanmıştır (16). Hem daha önce yapılan hem de bizim çalışmamızın sonuçlarına bakıldığında; hastaların çoğunluğunun yaşamın ilk 6 ayında semptomatik olduğu ve iki yaşına kadar tanı aldığı görülmektedir.

Başka bir çalışmada, 693 KF hastanın 15 tanesinde klinik olarak hepatik hastalık meydana gelmiş, 13 hastada tüm semptomların portal hipertansiyona sekonder oluştuğu saptanmıştır (14). Çalışmamızda KF tanısı alan hastalardan sadece ikisinde hepatobiliyer sistem tutulumu olup, bu hastalarda sadece asemptomatik hipertransaminazemi olduğu görüldü.

Psödobartter sendromu, terde artmış elektrolit kaybına bağı hipokloremi, hiponatremi ve hipoalbuminemiye eşlik eden renin ve aldosteronda artıș ile karakterize metabolik alkaloz tablosudur. Bazı hastalara intravenöz SIVı tedavisi gerekebilirken; bu hastalara hayatın ilk dönemlerinde ek sodyum ve potasyum verilmelidir. Bir yaşından sonraki dönemde bu tablo genellikle kendiliğinden düzelir $(17,18)$. 12 KF hastasının değerlendirildiği bir çalıșmada 8 hastada psödobartter sendromu saptanmıştır (16). Çalışmaya aldığımız hastaların 15'inde psödobartter sendromu mevcutken; bu hastaların sadece 2'sinde KF tanısı konuldu.

Avrupa tanısal çalışma grubu KF tanısında terminolojik önerilerde bulunurken, KF hastalarını klasik (tipik) ve nonklasik (atipik) olarak iki sınıfa ayırmıştır. Atipik KF tanısı için, KF için bir fenotipik özellik, en az bir sistem tutulumunu ve normal ya da sınırda pozitif ter testi ölçümünü gerekli görmüş ve bu hastalarda kesin tanı konulması için KFTR mutasyon çalışmaları veya nazal potansiyel fark ölçümü 
gibi diğer tanısal yöntemlerin kullanılmasını önermiştir (19). KF tanısında tek bir ter testi yüksekliği tanı koymada yeterli değildir, bütün yüksek ve sınırda pozitif ter testi sonuçları en az iki kez farklı zamanda tekrar edilmelidir (20). Çalışmamızda terde kondüktivite ölçümü yöntemiyle ter testi yapılmıştır. Değerlendirmede; 60-79 mmol/lt sınırda pozitif ölçüm, $80 \mathrm{mmol} / \mathrm{lt}$ 'nin üzeri pozitif ve $59 \mathrm{mmol} / \mathrm{lt}$ 'nin altı negatif ölçüm olarak alınmıştır. Tüm pozitif ve şüpheli hastalara en az 2 kez ter testi yapılmıştır. Toplam 356 hastaya 430 ter testi yapıImıș olup 5 hastaya tipik KF tanısı konmuş, 15 hasta ise atipik KF olarak takibe alınmıștır. Illk ter testi $80 \mathrm{mmol} / \mathrm{lt}$ üzerinde ölçülen altı hastadan birisinin kontrol ter testleri iki kez normal olduğu için yanlış pozitiflik olarak kabul edildi ve KF tanısı konulmadı. Ayrıca, ilk test sonuçları 60-80 mmol/lt arasında olan 27 hastanın tümünün ter testleri tekrarlandı ve genetik mutasyonları gönderildi. Ter testi pozitifliği, genetik mutasyon, pankreatik elastaz düzeyleri ve hastaların fenotipik özellikleri göz önünde bulundurularak 15 hastaya atipik KF tanısı konuldu. Genetik inceleme sonucunda on iki hastada KF ile uyumlu mutasyon saptandı, üç hastada mutasyon saptanmadığı halde klinik özellikler ve tekrarlayan ter testleri 60-80 $\mathrm{mmol} / \mathrm{lt}$ arasında ölçüldüğü için atipik KF kabul edildi. Ülkemizde KFTR geninde görülen mutasyonların farklı olması ve 0 dönemde bakılan genetik mutasyon sayısının kısıtlı olması bu hastalarda mutasyon saptanmamasının bir nedeni olabilir.

KF insidansı toplumlar, ırklar ve hatta aynı ülkenin değişik bölgeleri arasında belirgin farklllık göstermektedir. Ülkemizde şimdiye dek KF insidansını saptamaya dönük ulaşabildiğimiz tek çalışma 1973 yılında Istanbul Üniversitesi'nden Gürson ve ark. (21) tarafından gerçekleştirilmiş ve terde klor iyonunun ölçülmesi ile insidans 1/3000 olarak bulunmuştur. Ülkemizde yapılan, riskli hasta grubunda KF sıklığının araştıııldığı bir çalışmada tekrarlayan akciğer enfeksiyonu olan çocuklarda KF sıklığı $\% 5,3$, malnutrisyonu olanlarda $\% 8,8$, malnutrisyonu ve/ veya tekrarlayan akciğer enfeksiyonu olan çocuklarda ise \%7,1 bulunmuştur (22). Ülkemizde yapılan iki çalışmada, tekrarlayan pnömonili hastalarda KF sıkığını \%3 ve $\% 12$ saptanmıştır $(23,24)$. Bir çalışmada kronik ishal vakalarında KF sıklığı \%10 bulunmuştur (25). KF açısından riskli hasta grubunda yaptığımız bu çalışmada, KF sıklığı tekrarlayan pnömonili hastalarda $\% 15,5$, gelişme geriliği olanlarda $\% 7$ ve kronik ishal yakınması olanlarda $\% 10,1$ saptanmış iken; değerlendirmeye alınan tüm hastalarda $\% 5,6$ olarak saptandı.

KF multisistemik bir hastalık olmakla birlikte mortalite ve morbiditeye en çok akciğer hastalığı sebep olmaktadır, KF'de akciğer hastalığının patogenezinin multifaktöriyel olduğu söylenebilir. Berkin ve arkadaşlarının erişkin ve adolesan dönemdeki KF hastaları üzerinde yaptığı çalışmada öksürük $\% 100$, balgam $\% 90$, sinüzit ve rinit
$\% 84$, parmaklarda çomaklaşma $\% 74$, krepitan raller $\% 42$, göğüs deformitesi \%26, tekrarlayan hışıltı (wheezing) \%58, eklem ağrısı \%68, abdominal distansiyon \%26, hepatomegali \%21, geç puberte \%10 saptamıştır (26). Suudi Arabistan'da yapılan çalışmada 12 KF hastasının tümünde tekrarlayan akciğer enfeksiyonu, gelişme geriliği ve kronik ishal saptanmıştır (16). Yine $106 \mathrm{KF}$ hastasının değerlendirildiği retrospektif bir çalışmada da en sık semptom olarak tekrarlayan akciğer enfeksiyonu, kronik ishal ve gelişme geriliği saptanmıştır (27). Brezilya'da 104 KF hastasının değerlendirildiği çalışmada ise hastaların \%89,4'ünde solunum sistem yakınması, \%59,6'sında sindirim sistem yakınması, \%5,8'inde mekonyum ileusu saptanmıştır (15). Çalışmamızda hem çalışmaya alınan hem de tanı alan hastalarda birçok sistemle ilgili şikâyet mevcut iken; ateş, solunum sistemi yakınmaları, gelişme geriliği ve kronik ishal temel başvuru yakınmalarıydı.

Sonuç olarak, kronik ishal, tekrarlayan akciğer enfeksiyonu ve gelişme geriliği ile başvuran hastalarda KF ayırıcı tanılar arasında düşünülmelidir. Riskli hasta grubunda yapılan bu çalışmada KF sıklı̆̆ı genel toplumdan yüksek saptanmıştır. Hastalığın klinik bulgularının erken yaşlarda başladığı dikkate alındığında tarama yöntemlerinin geliştirilip yaygınlaştırıması toplum sağığı açısından çok önemlidir.

\section{Kaynaklar}

1. Welsh MJ, Tsui L, Boat TF, et al. Cystic fibrosis. In Seriver CR, Beaudet AL, Sly WS, et al., eds. The metabolic and molecular bases of inherited disease. 7th ed. New York: McGraw Hill, 1995:3799-3876.

2. Lannuzzi MC, Cystic fibrosis: Genetics. In: Davis PB, ed. Cystic fibrosis. New York: Marcel Dekker, 1993;1-27.

3. Stern RC. The diagnosis of cystic fibrosis. N Engl J Med 1997;336:487-91.

4. Wallis C. Diagnosing cystic fibrosis: blood, sweat, and tears. Arch Dis Child 1997;76:85-8.

5. Rosenstein BJ, Cutting GR. The diagnosis of cystic fibrosis: a consensus statement. Cystic Fibrosis Foundation Consensus Panel. J Pediatr 1998;132:589-95.

6. Davis PB, Drumm M, Konstant MW. Cystic fibrosis: State of the art. Am J Respir Crit Care Med 1996;154:1229-56.

7. Wald ER. Recurrent and nonresolving pneumonia in children. Semin Respir Infect 1993;8:46-58.

8. Shwachman H, Kulczycki LL. Long term study of one hundred five patients with cystic fibrosis. AMA J Dis Child 1958;96:6-15.

9. Benden C, Wallis C, Owens CM, Ridout DA, Dinwiddie R. The Chrispin-Norman score in cystic fibrosis: doing away with the lateral view. Eur Respir J 2005;26:894-7.

10. Neyzi O, Günöz H, Furman A, Bundak R, Gökçay G, Darendeliler $F$, ve ark. Türk çocuklarında vücut ağırlğı, boy uzunluğu, baş çevresi ve vücut kitle indeksi referans değerleri. Çocuk Sağlığı ve Hastalıkları Dergisi 2008;51:1-14. 
11. Cystic Fibrosis Foundation. Patient Registery: 2004 Annual Data Report. Bethesda, MD. Cystic Fibrosis Foundation, 2005.

12. Walkowiak J, Nousia-Arvanitakis S, Henker J, Stern M, Sinaasappel M, Dodge JA. Indirect pancreatic function tests in children. J Pediatr Gastroenterol Nutr 2005;40:107-14.

13. Pawellek I, Dokoupil K, Koletzko B. Prevalence of malnutrition in paediatric hospital patients. Clin Nutr 2008;27:72-6.

14. Stern RC, Stevens DP, Boat TF, Doershuk CF, Izant RJ Jr, Matthews LW. Symptomatic hepatic disease in cystic fibrosis: incidence, course, and outcome of portal systemic hunting. Gastroenterology 1976;70:645-9.

15. Alvarez AE, Ribeiro AF, Hessel G, Bertuzzo CS, Ribeiro JD. Cystic fibrosis at a Brazilian center of excellence: clinical and laboratory characteristics of 104 patients and their association with genotype and disease severity. J Pediatr (Rio J) 2004:80:371-9.

16. Al-Mobaireek KF, Abdullah AM. Cystic fibrosis in Saudi Arabia: common and rare presentations. Ann Trop Paediatr 1995;15:269-72.

17. Devlin J, Beckett NS, David TJ. Elevated sweat potassium, hyperaldosteronism and pseudo-Bartter's syndrome: a spectrum of disorders associated with cystic fibrosis. J R Soc Med 1989;82 Suppl 16:38-43.

18. Simopoulos AP, Lapey A, Boad TF, Santagnese PAD, Bartter FC. The renin-angiotensin-aldosterone system in patients with cystic fibrosis of the pancreas. Pediatr Res 1971;5:626-8.
19. De Boeck K, Wilschanski M, Castellani C, Taylor C, Cuppens $\mathrm{H}$, Dodge J, et al. Cystic fibrosis: terminology and diagnostic algorithms. Thorax 2006;61:627-35.

20. Wallis C. Diagnosis and presentation of cystic fibrosis. In: Chernick V, Boat TF, Wilmolt RW, and Bush A, eds. Kendig's Disorders of the Respiratory Tract in Children. 7th Ed. Philadelphia: W.B. Saunders; 2006. p.866-72.

21. Gürson CT, Sertel H, Gürkan M, Pala S. Newborn screening for cystic fibrosis with chloride electrode and neutron activation analysis. Helv Paediatr Acta 1973;28:165-74.

22. Cesur Y, Doğan M, Arıyuca S, Peker E, Okur M, Akbayram S, ve ark. Hastaneye Başvuran Malnutrisyonu ve/veya Tekrarlayan Akciğer Enfeksiyonu Olan Çocuklarda Kistik Fibrozis Sıkı̆̆ı Araştırıması. Selçuk Ünv Tıp Derg 2010;26:138-41.

23. Çelebi S, Hacımustafaoğlu M, Albayrak Y, Bulur N. Çocuklarda Tekrarlayan Pnömoni. Çocuk Enf Derg 2010;4:56-9.

24. Ciftci E, Günes M, Köksal Y, Ince E, Dogru U. Underlying Causes of Recurrent Pneumonia in Turkish Children in a University Hospital. J Trop Pediatr 2003;49:212-5.

25. Altuntas B, Gül H, Yarali N, Ertan U. Etiology of chronic diarrhea. Indian J Pediatr 1999;66:657-61.

26. Berkin KE, Alcoc SR, Stack BH. Cystic fibrosis a review of 26 adolescent and adult patients. Eur J Respir Dis 1985;67:10311.

27. Hill ID, MacDonald WB, Bowie MD, Ireland JD. Cystic fibrosis in Cape Town. S Afr Med J 1988;73:147-9. 